\title{
Observations on the hatching dynamics and phenology of co-occurring large branchiopods from a small temporary pool in western India using ex situ sediment rehydration
}

\author{
Rushikesh Bhusnale ${ }^{1,2} \uparrow$, Aniket Marathe $2,3 \dagger$, Mihir R. Kulkarni ${ }^{2} \dagger$, Sameer M. Padhye $^{3,4} \dagger$ \\ and Kalpana Pai $^{2 *}$ \\ 1 Department of Zoology, S.S.G.M. College, Kopargaon, Ahmednagar-423601, Maharashtra, India \\ 2 Department of Zoology, Centre of Advanced Studies, Savitribai Phule Pune University, Pune 411007, Maharashtra, India \\ 3 Department of Zoology, Prof. Ramkrishna More Arts, Commerce and Science College, Akurdi, Pune 411044, Maharashtra, India \\ ${ }^{4}$ Wildlife Information Liaison Development Society, Coimbatore 641035, Tamil Nadu, India
}

Received 28 April 2016; Accepted 22 July 2016

\begin{abstract}
Sediment rehydration is a useful technique to study various ecological aspects of resting egg banks of many aquatic invertebrates, but there is a paucity of such studies from the Asian region as compared with other regions. Hence, using a tropical temporary pool as a study system, and with successive, ex situ hydrations of sediments, we studied (1) the hatching phenology and dynamics of co-occurring Notostraca and Anostraca, and (2) the effects of cyclical hydroperiods on these dynamics. Ten species of different aquatic taxa emerged from the sediments. Among the large branchiopods, the primary consumer Streptocephalus dichotomus (Anostraca) was more numerous than the predatory Triops granarius (Notostraca). However, while differing in ecological roles, the two species exhibited similar phenology and hatching strategies, with nauplii emerging in similar proportions across hydration treatments, peaking at the first hydration $(\sim 90 \%)$, and decreasing through the third. Hatching began on day 1 in all hydrations and peaked on days $2-3$. Hatching duration decreased with successive hydrations, being the longest for the first hydration. These species are important to the food chain associated with temporary aquatic habitats, which are relatively understudied in the Indian context. Laboratory-based studies, in combination with field data can help understand the ecology of the associated community. We highlight the need for such studies that can prove important for conservation of such habitats, when their destruction is rampant and undocumented.
\end{abstract}

Key words: Rehydration / large branchiopods / bet hedging / conservation / egg banks

\section{Introduction}

Temporary water bodies include a diverse spectrum of habitats ranging from phytotelmata to floodplain lakes. Despite differences in size and other parameters, the cyclical nature of the dry phase remains an important defining feature of such habitats (Williams, 2006). Temporary water bodies have been known to contribute significantly to regional diversity, often by supporting unique biota (Williams, 2006; Cereghino et al., 2008).

Numerous invertebrates inhabiting temporary water bodies propagate via production of long-lived resting eggs that form deposits or 'egg banks', facilitating their survival during harsh environmental conditions and forming

*Corresponding author: drkalpanapai@gmail.com

$\dagger$ These authors contributed equally to this work. important 'archives' for the biota (Brendonck and De Meester, 2003; Williams, 2006). This property of resting eggs can be exploited by artificially hydrating the sediments/eggs to simulate natural inundation, thereby providing the necessary cues for egg hatching (osmotic pressure, temperature, etc. see Brendonck, 1996) and emergence of biota. This 'sediment rehydration' method is being used increasingly in studies on aquatic invertebrates, especially from understudied habitats (Waterkeyn et al., 2009) owing to its simplicity, cost-effectiveness and efficacy in assessing diversity (see García-Roger et al., 2008).

Sediment rehydration has also been used extensively to study ecological and evolutionary aspects of egg banks (Simovich and Hathaway, 1997; Mura, 2001, 2004; Rossi et al., 2004, 2012; Zarattini, 2004; Zarattini and Mura, 2007) in these Crustacea (see Brendonck and 
De Meester, 2003 for a review). Only few such studies have been carried out from the Asian region (Saengphan et al., 2005; Wang and Chou, 2015), while most data are available from the temperate zone. Studies from India are much rarer (Bernice, 1972; Sam and Krishnaswamy, 1979). The nature of Indian freshwater habitats, driven by the unique and quite predictable 'monsoons', necessitates further studies from this region especially with respect to hatching phenology of different species.

Furthermore, such habitats face tremendous pressure from ongoing anthropogenic activities, which often leads to their destruction owing to changes in land-use patterns, pollution etc., especially in developing, tropical countries like India. The lack of awareness regarding these habitats and their destruction makes reports of baseline data from these habitats crucial.

Therefore, we carried out this study with the following objectives: (1) to describe the hatching dynamics of co-occurring Notostraca and Anostraca, and (2) to study the effects of successive cyclical hydroperiods on these dynamics.

\section{Materials and methods}

The temporary pool is located on Alandi road just on the outskirts of Pune city $\left(18^{\circ} 38^{\prime} 21.23^{\prime \prime} \mathrm{N} \& 73^{\circ} 52^{\prime} 42.29^{\prime \prime} \mathrm{E}\right)$ (Image 1; refer to Padhye et al., 2011 for details). This site was sampled infrequently when inundated from 2009 to 2015 using standard methods (see Kulkarni et al., 2015 for details), and identified fauna was recorded. However, it should be noted that this habitat was destroyed in 2015 as it was used as a landfill.

Dry sediments (upper $2 \mathrm{~cm}$; see Brendonck and De Meester, 2003; Mura, 2005) were scraped off using a clean garden spade from the centre as well as the sides of the pool after the pool had been dry for about a month. Approximately $0.5 \mathrm{~kg}$ of sediment was collected at a time. These sediments were sun-dried for a week to ensure complete drying and stored at room temperature in closed plastic bags. Sediments were collected in 2013 and 2014, and both samples were stored separately.

\section{Rehydration and monitoring}

Rehydration of sediments was carried out following the modified Sars method (Van Damme and Dumont, 2010). The larger sediment chunks were lightly homogenized and hydrated. Two different setups were used: (1) $300 \mathrm{~g}$ of sediments (collected in 2013) were hydrated with $10 \mathrm{~L}$ aged tap water in aquaria $(n=3)$ and monitored for a month to initially document emergent fauna associated with this pool, and (2) $4 \mathrm{~g}$ of sediment (collected in 2014) were hydrated with $400 \mathrm{~mL}$ aged tap water in $500 \mathrm{~mL}$ glass beakers $(n=12)$ to specifically document the hatching phenology of the two dominant large branchiopod species present. Both setups were kept at ambient conditions (temperature range: $24-28^{\circ} \mathrm{C}$; photoperiod range: 11:13-12:12 L:D).
The setups were monitored daily for emergence of large branchiopods (see Figs. 1(B) and (C)) as well as other animal groups. One litre of water was drawn randomly (10 aliquots of $100 \mathrm{~mL}$ ) from the aquaria, filtered through a $40 \mu \mathrm{m}$ mesh, and the filtrate was examined under a stereo microscope to identify the emergent fauna. Similarly, nauplii of both species were enumerated by filtering the water from the beakers through a $40 \mu \mathrm{m}$ mesh, and examining under a stereomicroscope $($ at $40 \times)$. Counted nauplii were kept separately, along with other species that had emerged. The filtered water was added back to the beaker, and the water level maintained with aged tap water.

Beakers were monitored for 8 days, after which the water was filtered out using a $40 \mu \mathrm{m}$ mesh and the sediments were allowed to sun-dry for 8 days before subsequent hydration. To ensure the absence of contamination with airborne cysts, a clean paper was tied over the mouth of the beakers while drying.

The procedure was repeated three times for each beaker, and designated as hydration 1, 2 and 3, respectively $(\mathrm{H} 1, \mathrm{H} 2, \mathrm{H} 3)$. H3 was carried out once with three beakers due to logistic constraints.

The total number of hatchlings of both species, obtained from all three hydrations constituted the total observed hatching (TOH). The hatching phenology was described using two parameters: initiation of hatching $\left(T_{0}\right)$ was the time (in days) after hydration when the first hatched nauplius was observed, and duration of hatching $\left(T_{\mathrm{d}}\right)$ was the time (in days) after $T_{0}$ until the last nauplius was observed.

\section{Analyses}

Identification of observed large branchiopods was done as per Padhye and Dahanukar (2015) and references therein. For details about identification of other taxa refer to Kulkarni et al. (2015).

The effect of successive hydration treatments on the proportional hatching of Triops granarius and Streptocephalus dichotomus was tested, the null hypothesis $\left(H_{0}\right)$ being 'Successive hydrations do not affect hatching proportions of $T$. granarius and $S$. dichotomus'. This was analysed using a contingency test for multiple proportions (see Zar, 2010). Data were log-transformed for graphical representation. Differences in $T_{\mathrm{d}}$ of both species were tested by the Kruskal-Wallis test. The effect of successive hydrations on $T_{\mathrm{d}}$ was analysed for both species (separately) by the Kruskal-Wallis test, followed by MannWhitney multiple comparisons. Analyses were performed using the freeware PAST (Hammer et al., 2001).

\section{Results}

\section{Faunistics}

Fifteen species of different aquatic invertebrate groups were observed in the field samples. These were dominated 

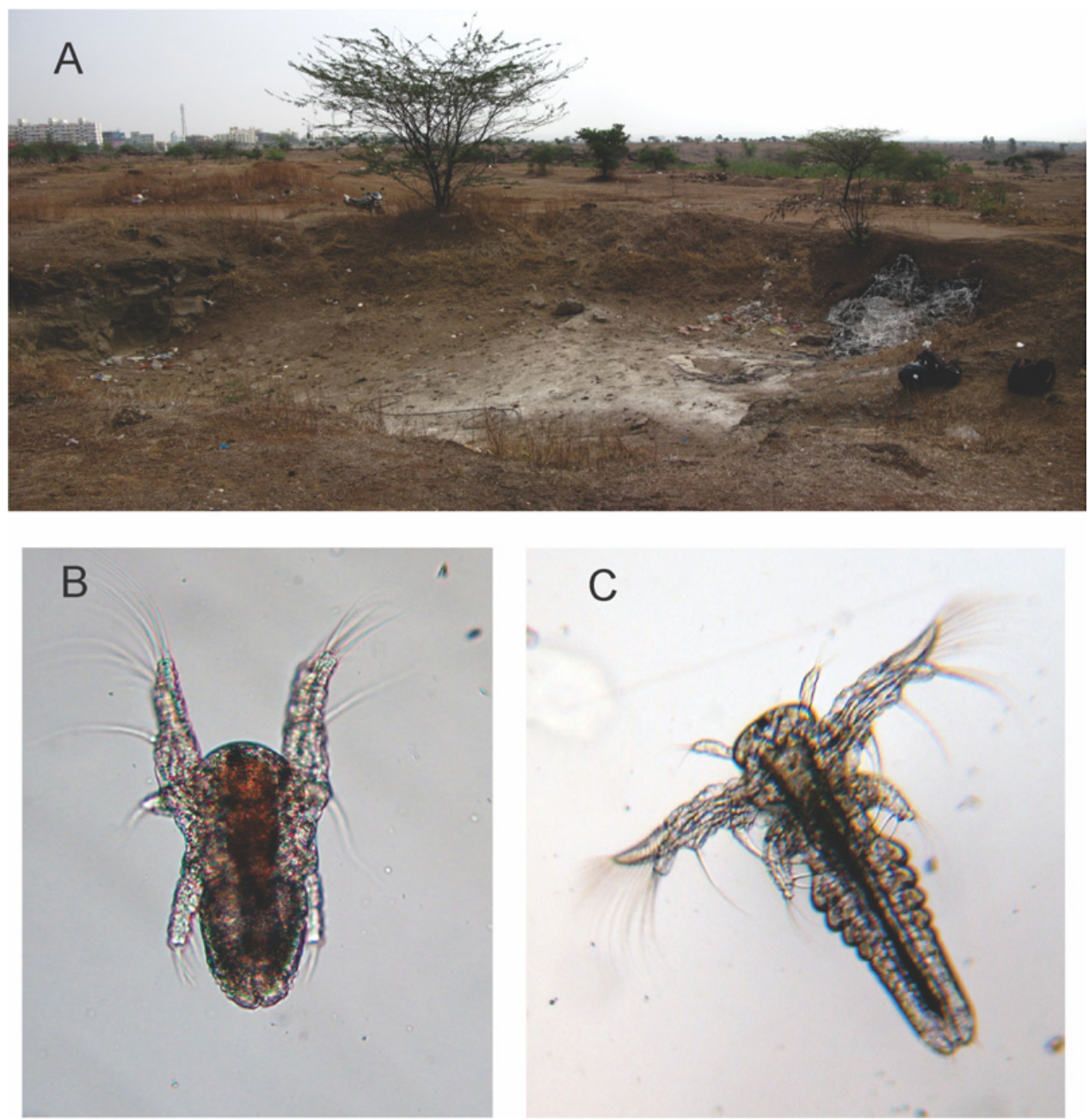

Fig. 1. (A) Study site in dry phase (courtesy S.S. Jakhalekar); (B) Nauplius of T. granarius; (C) Metanauplius of S. dichotomus. Images $\mathrm{B}, \mathrm{C}$ taken at $100 \times$ final magnification (courtesy S.M. Padhye).

by the Branchiopoda (Cladocera - 5 sp. and large branchiopods - 5 sp.) (S.M.P. and M.R.K. personal observation). Twelve species emerged from the sediments hydrated in the aquaria, consisting of three copepods, three cladocerans, three rotifers and three large branchiopods (see Table 1). Among the latter, S. dichotomus was the most abundant, followed by $T$. granarius and Leptestheria nobilis respectively; L. nobilis being the rarest. In the cyclical hydration treatments, $S$. dichotomus and $T$. granarius were observed along with the rotifer Brachionus quadridentatus, $S$. dichotomus being most abundant. Other species known to emerge were not observed in the period of experimental hydrations.

\section{Hatching dynamics and phenology of S. dichotomus and $T$. granarius}

A total of 8694 S. dichotomus nauplii and 2076 T. granarius nauplii hatched from $48 \mathrm{~g}$ of sediment (12 beakers) after three cycles of hydration-drying.
Hatching started $\left(T_{0}\right)$ on day 1 (within 20-24 h) for both species (see Table 2). For each hydration, most nauplii $(\sim 90 \%)$ emerged in $4-5$ days post-inundation, with emergence peaking on day 2 (Fig. 2(A)). The number of emerging nauplii decreased with repeated hydration, the most $(>90 \%$ of $\mathrm{TOH}$ ) emerging in the first hydration itself (Fig. 2(B)). Hatching duration decreased with successive hydrations (see Table 2 and Figs. 2(C) and (D)), and was significantly different across hydrations (KruskalWallis test; for both $T$. granarius (Tgr) and S. dichotomus (Sdi): $P($ same $)<0.0001$; Table 3 and Figs. 2(C) and (D)). Hatching duration for the first hydration was significantly different from that for the second and the third. However, hatching duration for the second and third hydration did not differ significantly (see Table 3, Figs. 2(C) and (D)). Hatching duration $\left(T_{\mathrm{d}}\right)$ of both species was not significantly different (Kruskal-Wallis test, $P=0.32$ ) from each other.

The number of hatching events (TOH) for both species ranged from a maximum for the first hydration to a minimum for the third hydration treatment. The number of hatched $T$. granarius nauplii was consistently lower 
Table 1. Faunistic summary of identified aquatic invertebrate species from the study habitat from field data and sediment rehydration; '+' indicates presence, ' -' indicates absence.

\begin{tabular}{|c|c|c|c|}
\hline Group & Species & Field data (2009-15) & Sediment rehydration (this study) \\
\hline \multirow[t]{3}{*}{ Copepoda } & Phyllodiaptomus blanci (Guerne and Richard, 1896) & + & + \\
\hline & Heliodiaptomus viduus (Gurney, 1916) & + & + \\
\hline & Mesocyclops sp. & + & + \\
\hline \multirow[t]{6}{*}{ Cladocera } & Moina micrura Kurz, 1874 & + & + \\
\hline & Leberis punctatus (Daday, 1898) & + & - \\
\hline & Leydigia (Neoleydigia) ciliata Gauthier, 1939 & + & - \\
\hline & Ceriodaphnia cornuta Sars, 1885 & + & + \\
\hline & Macrothrix spinosa King, 1853 & + & - \\
\hline & Daphnia (Ctenodaphnia) similoides Hudec, 1991 & - & + \\
\hline \multirow[t]{3}{*}{ Rotifera } & Asplanchna sp. & - & + \\
\hline & Brachionus sp. & + & + \\
\hline & Brachionus quadridentatus Hermann, 1783 & + & + \\
\hline Notostraca & Triops granarius (Lucas, 1864) & + & + \\
\hline Anostraca & Streptocephalus dichotomus Baird, 1860 & + & + \\
\hline Laevicaudata & Lynceus denticulatus (Gurney, 1930) [species complex] & + & - \\
\hline \multirow[t]{2}{*}{ Diplostraca } & Cyzicus annandalei Daday, 1913 & + & - \\
\hline & Leptestheria nobilis Sars, 1900 & + & + \\
\hline
\end{tabular}

than that of $S$. dichotomus for all hydrations (Figs. 2(A) and (B)). The relative proportions of hatched $T$. granarius and $S$. dichotomous did not differ significantly among the three hydration treatments (contingency test for multiple proportions, $P=0.17$ ).

\section{Discussion}

Our results showed that the two species we studied, despite belonging to different orders (Notostraca and Anostraca, respectively) and differing in their ecology (see Dumont and Negrea, 2002), showed a very similar hatching phenology, especially with regard to the initiation and duration of hatching.

The immediate initiation and proportion of hatching can be an indicator of the predictable inundations of the habitat, an important driver of the evolution of hatching phenologies. The probability of a 'good year', i.e., a hydroperiod long enough for successful recruitment and replenishment of the egg bank has been considered in models of egg bank dynamics (see Simovich and Hathaway, 1997). A predictable inundation and sufficiently long hydroperiod, both of which are observed in this habitat owing to the 4-month long monsoons (Mani, 1974), can lower the chances of abortive hatching. A similar pattern has previously been reported for the same species ( $S$. dichotomus) from south India (Bernice, 1972; Sam and Krishnaswamy, 1979), with emergence of nauplii ranging from 78 to $100 \%$, and following similar initiation and duration of hatching. Whether or not this pattern fits the definition of 'bet hedging' can be better clarified after similar experiments on sediments from unpredictable habitats in this region. Initiation of hatching is observed to differ across habitats, and is often delayed in unpredictable (true ephemeral) systems (see Simovich and Hathaway, 1997). Indeed, hatching seems to begin right at the start of inundation in temporary pools in India, also with higher hatching fractions (see Bernice, 1972; Sam and Krishnaswamy, 1979; this study). In combination, although they can be considered to reflect the relatively high predictability and stability of inundations, they also entail a significant risk to the populations. Early emergence with a higher hatching fraction indicates a lower 'reserve' fraction, which in turn can make the recovery of the population following erratic, short inundations difficult. Such events are likely to be triggered by changing climatic patterns, and can potentially lead to local extinction of populations, especially in Indian temporary waters.

The patterns of emergence for $T$. granarius and $S$. dichotomus can also be influenced by their egg bank compositions. Reported fecundities of Triops numidicus (300-350) (see Dumont and Negrea, 2002) and S. dichotomus (200-900) (see Bernice, 1972) differ widely. We did not measure fecundities of $T$. granarius and $S$. dichotomus in our study, but assuming numbers similar to the reported values for $T$. numidicus and $S$. dichotomus, respectively (see above), the observed numerical differences in total emergence of the species can be expected. The species' roles in the aquatic food web can give a better ecological perspective on this phenomenon. T. granarius is predominantly considered to be a predator, while $S$. dichotomus is a filter feeder (see Dumont and Negrea, 2002), which can in turn govern their life histories and thus fecundities - the predator being less fecund than the primary consumer.

Observations of peak emergence in the early inundation period have been reported for various large branchiopods by Bernice (1972 - South India), Hildrew (1985 - Kenya), Brendonck (1996) and Waterkeyn et al. (2009 - Mediterranean wetlands). Emergence can also be affected by the 'age structure' of the egg banks (Brendonck and De Meester, 2003), and also by the brood from which the eggs are derived (Saengphan et al., 2005-Anostraca); however, we do not account for these factors. 

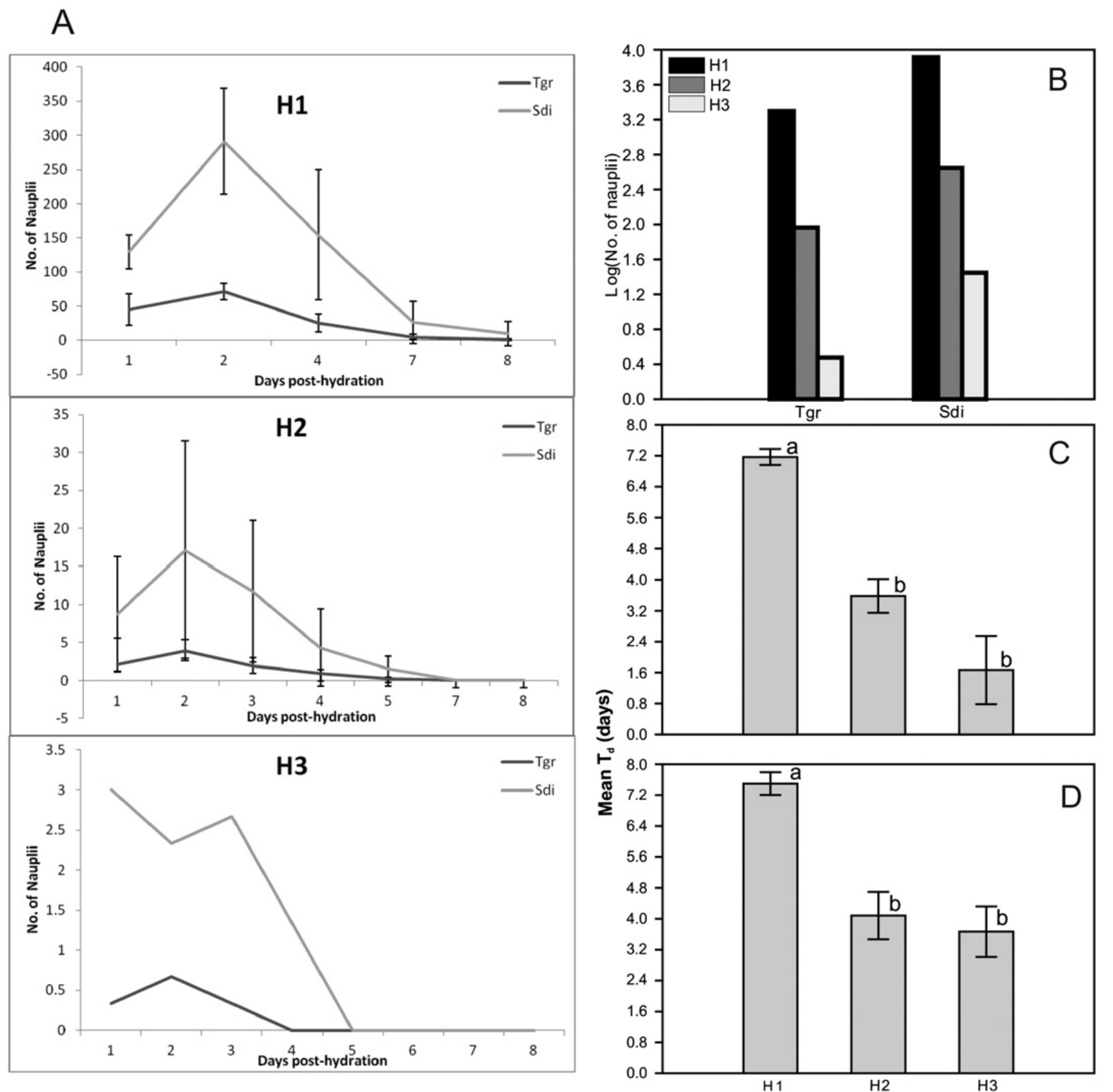

Fig. 2. (A) Hatching pattern (No. of nauplii as mean \pm S.E.) of T. granarius (Tgr) and S. dichotomus (Sdi) over hydrations H 1-3; (B) Hatching pattern (Log No. of nauplii) of T. granarius (Tgr) and S. dichotomus (Sdi) over hydrations (H 1-3); Effect of successive hydrations $(\mathrm{H} 1-3)$ on the hatching duration $\left(T_{\mathrm{d}}\right.$, mean \pm S.E.) of $(\mathrm{C}) T$. granarius and (D) S. dichotomus. Letters indicate significant differences (Mann-Whitney multiple comparisons).

Table 2. Hatching phenology of $T$. granarius (Tgr) and S. dichotomous (Sdi). $T_{0}-$ Hatching initiation (days); $T_{\mathrm{d}}-$ Hatching duration (days).

\begin{tabular}{lccccc}
\hline & \multicolumn{3}{c}{ Phenology parameters (Mean) } \\
\cline { 2 - 3 } \cline { 5 - 6 } Hydration & \multicolumn{3}{c}{$T_{0}$} & & \multicolumn{3}{c}{$T_{\mathrm{d}}$} \\
\cline { 2 - 3 } \cline { 5 - 6 } & Tgr & Sdi & & Tgr & Sdi \\
\hline 1 & 1 & 1 & & 7.4 & 7.53 \\
3 & 1 & 1 & & 3.73 & 4.13 \\
\hline
\end{tabular}

Table 3. Pairwise differences between $T_{\mathrm{d}}$ across hydrations (Mann-Whitney multiple comparison, Bonferroni corrected $p$ values). Numbers above diagonal for $T$. granarius; numbers below diagonal for $S$. dichotomous. Significant results in boldface. H1, 2 and 3 denote three successive hydrations.

\begin{tabular}{llll}
\hline & H1 & H2 & \multicolumn{1}{c}{ H3 } \\
\hline H1 & & $\mathbf{0 . 0 0 0 2 7 2}$ & $\mathbf{0 . 0 2 5 1 3}$ \\
H2 & $\mathbf{7 . 0 E - 0 5 ~}$ & & 0.2242 \\
H3 & $\mathbf{0 . 0 2 0 6 1}$ & 1 & \\
\hline
\end{tabular}


We did not isolate eggs from sediments for the experiments as this has been reported to influence hatching dynamics (see Vandekerkhove et al., 2004). Hence, it is quite likely that the relatively 'conserved' patterns observed do reflect the natural dynamics, but more detailed data are needed.

An extensive review exists for the details of hatching phonologies of many large branchiopods (Brendonck, 1996) wherein it is clearly seen that studies from the tropical region, especially from the Indian subcontinent are few. Data on important phenology parameters such as hatching initiation and duration are unavailable for many species. New data, especially from the understudied regions could prove to be very useful for better understanding the ecological processes influencing these phenomena (see Brendonck, 1996). This is especially clear in the case of the number of emergent nauplii - Hildrew (1985) observed a maximum hatching of over 500 eggs of Streptocephalus vitreus from sediment cores from an African pool; Waterkeyn et al. (2009) observed a maximum of 4 (mean) hatchlings of Triops cancriformis from sediments of Mediterranean temporary wetlands. On the other hand, we observed the hatching of over 2000 T. granarius and $8000 \mathrm{~S}$. dichotomus nauplii from a small (48 g) quantity of sediment, over $400 T$. granarius and well over $1500 \mathrm{~S}$. dichotomus nauplii hatching from a single hydration of just $4 \mathrm{~g}$ of sediment. This highlights the effects of the distinct climatic conditions in our region, where a quite predictable monsoon phase occurs.

Temporary water bodies are dynamic ecosystems as they are often subjected to fluctuating environmental conditions, resulting in the evolution of specialized communities in these habitats. The communities are largely shaped by the hydro-dynamics of the habitat, and compositions can change drastically in the event of unpredictable hydrations. A change in community structure can have profound consequences at the ecosystem level due to large alterations or collapse of food webs. Laboratory-based studies on such processes can easily be carried out using the sediment-rehydration approach, the data from which can be immensely helpful in understanding not only the community level processes and influence of environmental conditions, but also in formulating conservation measures.

Temporary water bodies are facing anthropogenic threats globally, being rampantly and rapidly destroyed owing to changes in land-use patterns, pollution and growing urbanization (see Williams, 2006; Brendonck et al., 2008). Despite their rich and unique biota, such habitats are also 'invisible' to conservation agencies (Marrone et al., 2006). In developing countries like India, there is a lack of public knowledge about these ecosystems, largely due to the lack of baseline data (see Kulkarni et al., 2015). This, coupled with the tremendous population and associated problems, has led to an overall 'indifference' with regard to such habitats. Similar studies on such threatened ecosystems must be encouraged, as they might play crucial roles in planning and implementing conservation strategies.
Acknowledgements. M. R. K. and S. M. P. are grateful to Late Prof. Graziella Mura (Sapienza University of Rome, Italy), Prof. Marie Simovich (San Diego University, USA), Dr. H. V. Ghate (Modern College, Pune-05, India) and Mr. Shriraj Jakhalekar (National Institute of Oceanography, Goa, India) for their helpful comments, and Ms. Kalyani Bhakare (Savitribai Phule Pune University, Pune) for her help in identifying rotifer species. This work was a part of MSc. dissertation projects of R. B. and A. M., at the Department of Zoology, Savitribai Phule Pune University, Pune. M. R. K. and S. M. P. thank the Council for Scientific and Industrial Research (CSIR, India), for research fellowships. S.M.P. acknowledges Dr. Sanjay Molur and the Wildlife Information Liaison Development Society for their support. K. P. is supported by the DST- PURSE, DRDP, UGCCAS and BCUD grants. All the authors thank the funding agencies for their support and the reviewers for their constructive comments.

\section{References}

Bernice R., 1972. Ecological studies on Streptocephalus dichotomus. Hydrobiologia, 39, 217-240.

Brendonck L., 1996. Diapause, quiescence, hatching requirements: what we can learn from large freshwater branchiopods (Crustacea: Branchiopoda: Anostraca, Notostraca, Conchostraca). Hydrobiologia, 320, 85-97.

Brendonck L. and De Meester L., 2003. Egg banks in freshwater zooplankton: evolutionaryand ecological archives in the sediment. Hydrobiologia, 491, 65-84.

Brendonck L., Rogers, D.C., Olesen, J., Weeks, S. and Hoeh, W.R., 2008. Global diversity of large branchiopods (Crustacea: Branchiopoda) in freshwater. Hydrobiologia, $595,167-176$.

Cereghino R., Biggs J., Declerck S. and Oertli B., 2008. The ecology of European ponds: defining the characteristics of a neglected freshwater habitat. Hydrobiologia, 597, 1-6.

Dumont H.J. and Negrea S.V., 2002. Branchiopoda. In: Dumont H.J. (ed.), Guides to the Identification of the Microinvertebrates of the Continental Waters of the World. Backhuys Publishers, Leiden, 398.

García-Roger E.M., Armengol-Díaz X., Carmona M.J. and Serra M., 2008. Assessing rotifer diapausing egg bank diversity and abundance in brackish temporary environments: an ex situ sediment incubation approach. Archiv für Hydrobiologie, 173, 79-88.

Hammer O., Harper D.A.T. and Ryan P.D., 2001. PAST: paleontological statistics software package for education and data analysis. Palaeontol. Elec., 4, 1-9.

Hildrew A.G., 1985. A quantitative study of the life history of a fairy shrimp (Branchiopoda: Anostraca) in relation to the temporary nature of its habitat, a Kenyan rainpool. J. Anim. Ecol., 54, 99-110.

Kulkarni M.R., Padhye S., Vanjare A.I., Jakhalekar S.S., Shinde Y.S., Paripatyadar S.V., Sheth S.D., Kulkarni S., Phuge S.K., Bhakare K., Kulkarni A.S., Pai K. and Ghate H.V., 2015. Documenting the fauna of a small temporary pond from Pune, Maharashtra, India. J. Threatened Taxa, 7, 7196-7210, Available online at: http://dx.doi.org/10.11609/JoTT.o4190.7196-210.

Mani M.S., 1974. Ecology and Biogeography in India, W. Junk Publishers, The Hague, 647 p. 
Marrone F., Barone R. and Naselli-Flores L., 2006. Ecological characterization and cladocerans, calanoid copepods and large branchiopods of temporary ponds in a Mediterranean island (Sicily, southern Italy). Chem. Ecol., 22, S181-S190.

Mura G., 2001. Life history strategy of Chirocephalus ruffoi (Crustacea, Anostraca) in Mediterranean temporary mountain pools. Hydrobiologia, 462, 145-156.

Mura G., 2004. Structure and functioning of the "Egg Bank" of a fairy shrimp in a temporary pool: Chirocephalus ruffoi from Pollino National Park (Southern Italy) as a case study. Int. Rev. Hydrobiol., 89, 35-50.

Mura G., 2005. Cyst distribution and hatching pattern of Chirocephalus ruffoi (Crustacea, Anostraca) in an experimental undisturbed pool. Int. Rev. Hydrobiol., 90, 277-291.

Padhye S.M. and Dahanukar N., 2015. Distribution and assemblages of large branchiopods (Crustacea: Branchiopoda) of northern Western Ghats, India. J. Limnol., 74, 371-380.

Padhye S.M., Ghate H.V. and Pai K., 2011. New locality records and additional information on habitats of three species of clam shrimps (Crustacea: Branchiopoda) from a region in northern part of Western Ghats (Sahyadris), India. J. Threatened Taxa, 3, 1756-1763.

Rossi V., Bartoli M., Bellavere C., Gandolfi A., Salvador E. and Menozzi P., 2004. Heterocypris (Crustacea: Ostracoda) from the Isole Pelagie (Sicily, Italy): hatching phenology of resting Eggs. Ital. J. Zool., 71, 223-231.

Rossi V., Albini D., Benassi G. and Menozzi P., 2012. To rest in hydration: hatching phenology of resting eggs of Heterocypris incongruens (Crustacea: Ostracoda). Fundam. Appl. Limnol., 181, 49-58.

Saengphan N., Shiel R.J. and Sanoamuang L.O., 2005. The cyst hatching pattern of the thai fairy shrimp, Branchinella thailandensis Sanoamuang, Saengphan \& Murugan, 2002 (Anostraca). Crustaceana, 78, 513-523.
Sam S.T. and Krishnaswamy S., 1979. Effect of osmomolarity of the medium upon hatching of undried eggs of Streptocephalus dichotomus Baird (Anostraca: Crustacea). Arch. Hydrobiol., 86, 125-130.

Simovich M.A. and Hathaway S.A., 1997. Diversified bethedging as a reproductive strategy of some ephemeral pool anostracans (Branchiopoda). J Crustac. Biol., 17, 38-44.

Van Damme K. and Dumont H.J., 2010. Cladocera of the Lenç óis Maranhenses (NE-Brazil): faunal composition and a reappraisal of Sars' Method. Brazillian J. Biol., 70, 755-779.

Vandekerkhove J., Niessen B., Declerck S., Jeppesen E., Conde Porcuna J.M., Brendonck L. and De Meester L., 2004. Hatching rate and hatching success with and without isolation of zooplankton resting stages. Hydrobiologia, 526, 235-241.

Wang C.C. and Chou L.S., 2015. Terminating dormancy: hatching phenology of sympatric large branchiopods in Siangtian pond, a temporary wetland in Taiwan. J. Crustac. Biol., 35, 301-308.

Waterkeyn A., Grillas P., de Roeck R.M., Boven L. and Brendonck L., 2009. Assemblage structure and dynamics of large branchiopods in Mediterranean temporary wetlands: patterns and processes. Freshwater Biol., 54, 1256-1270.

Williams D.D., 2006. The Biology of Temporary Waters, Oxford University Press, New York.

Zar J.H., 2010. Biostatistical Analysis (5th edn), Pearson Education Inc., New Jersey.

Zarattini P., 2004. Intraspecific differences in hatching phenology of the fairy shrimp Chirocephalus diaphanus Prévost, 1803 (Crustacea, Anostraca) in relation to habitat duration. J. Limnol., 63(Suppl. 1), 85-89.

Zarattini P. and Mura G., 2007. Co-occurrence of free-swimming and quiescent nauplii in a spring hatching of two chirocephalus diaphanus Prévost, 1803 (Anostraca) populations from mountain pasture pools. Crustaceana, 80, 707-715. 